\title{
A JUSTIÇA AMBIENTAL E SUA RELAÇÃO COM O DIREITO SOCIOAMBIENTAL
}

\author{
Rogério Santos Rammê* \\ Caroline Zalazar**
}

\begin{abstract}
RESUMO
O presente artigo analisa o conteúdo normativo do direito socioambiental a partir das perspectivas da justiça ambiental e do socioambientalismo. Analisa ainda, o direito socioambiental na perspectiva constitucional, identificando um sistema de direitos e deveres fundamentais de natureza coletiva ou difusa, fundados na multietnicidade e no pluralismo. Nesse sentido, abarca um conjunto de normas jurídicas destinadas à proteção da biodiversidade e da sociodiversidade (étnica e cultural). Contudo, muito embora a existência de um marco jurídico-constitucional socioambiental no Brasil, resultado da convergência necessária da tutela dos direitos sociais e dos direitos ambientais num mesmo projeto jurídico-político, na prática tais direitos e deveres são constantemente violados, acarretando um grande número de conflitos socioambientais, a demonstrar que há uma desconexão entre o projeto jurídico-político nacional e a realidade.
\end{abstract}

PALAVRAS-CHAVE: Justiça Ambiental; Socioambientalismo; Vulnerabilidade; Direito Socioambiental.

\footnotetext{
* Advogado. Professor de Direito no Centro Universitário Metodista do IPA.

** Discente do Curso de Direito do Centro Universitário Metodista do IPA.
} 


\begin{abstract}
This article analyzes the normative content of the social and environmental right from the perspectives of environmental justice and socioenvironmentalism. It also examines the social and environmental law in constitutional perspective, identifying a system of fundamental rights and duties of collective or diffuse nature, founded on multi-ethnicity and pluralism. In this sense, cover a set of juridical norms for the protection of biodiversity and social diversity (ethnic and cultural) in Brazil. However, even though the existence of a social and environmental constitutional framework in Brazil, a result of the necessary convergence of the protection of social rights and environmental rights in the same legal and political project, in practice these rights and duties are constantly violated, causing a large number of social and environmental conflicts, to demonstrate that there is a disconnect between the national legal-political project and the reality.
\end{abstract}

KEYWORDS: Environmental justice; Socioenvironmentalism; Vulnerability; Social and Environmental Law.

\title{
1. INTRODUÇÃO
}

A proteção do meio ambiente vem se tornando cada vez mais necessária em nossa sociedade, tendo em vista o aumento dos níveis de poluição, de perda de biodiversidade e das recentes mudanças climáticas, situações que tem acarretado consequências inimagináveis à qualidade de vida e ao bem estar dos seres humanos que habitam o planeta.

Há um certo senso comum bastante difundido, no sentido de que a poluição e os impactos ambientais são "problemas democráticos", que atingem a todos indiscriminadamente. Contudo, a ideia de repartição equitativa dos riscos ambientais está longe de corresponder à realidade. Percebe-se cada vez mais que a poluição e a degradação do meio ambiente não atingem a todos os grupos sociais de maneira uniforme, bem como não os submetem aos mesmos riscos e incertezas. Existe, portanto, uma grande dose de iniquidade na repartição das cargas ambientais negativas no cenário social. 
Paradoxalmente, identifica-se no âmbito do constitucionalismo pátrio uma recente inclinação doutrinária a apontar o surgimento de um marco jurídico-constitucional socioambiental, resultado da convergência necessária da tutela dos direitos sociais e dos direitos ambientais num mesmo projeto jurídico-político.

Nesse contexto, ganha relevo a perspectiva da justiça ambiental, e os demais valores do socioambientalismo, os quais desafiam o jurista desse tempo a compreender o âmbito de proteção dos direitos e deveres fundamentais socioambientais, bem como a buscar estratégias jurídicas capazes de garantir sua concretização.

Para tanto, o presente ensaio pretende demonstrar que o direito socioambiental é uma realidade que precisa ser definitivamente compreendida pelos operadores do direito pátriotendo em vista sua evidente falta de efetividade.

Casos como os da Hidrélétrica de Belo Monte, da transposição do Rio São Francisco, da Barragem de Mariana, dentre muitos outros, são emblemáticos no Brasil como exemplos negativos empreendimentos ou atividades ligadas ao atual modelo de desenvolvimento nacional, que acarretam inúmeros conflitos e injustiças socioambientais. Conflitos e injustiças que decorrem da desigual distribuição do risco ambiental no cenário social e que evidenciam que apesar da Constituição Federal de 1988 estabelecer as bases de um Estado Socioambiental e Democrático de Direito no Brasil, continuamos a assistir, dia a dia, as populações pobres e socialmente vulneráveis sofrerem injustas violações de direitos humanos em contextos de degradação ambiental.

É por essa razão que abordar a relação existenteentre a temática da justiça ambiental e os direitos e deveres fundamentais socioambientais cada vez mais se mostra essencial.Trata-se, na verdade, de um desafio aos juristas desse tempo: tornar a justiça ambiental também uma preocupação jurídica, bem como desenvolver instrumentos e técnicas jurídicas capazes de promovê-la, 
à luz do marco constitucional socioambiental que estrutura o Estado de Direito brasileiro.

\section{SOCIOAMBIENTALISMO E JUSTIÇA AMBIENTAL COMO NÚCLEO DO DIREITO SOCIOAMBIENTAL}

O socioambientalismo no Brasil, ganha força em meados dos anos 80, identificando-se com o processo de redemocratização do país, com o final do regime militar e com o advento da Constituição Federal de 1988. Nesse período, floresceu uma aproximação discursiva no âmbito dos movimentos sociais e ecológicos, fruto da percepção de que os conflitos referentes à questão ambiental não devem ser encarados somente como crises relacionadas à escassez de recursos naturais, riscos ambientais ou à poluição e ao desequilíbrio ecológico; mas também como crises afetas à apropriação e significação dos recursos naturais por diferentes atores sociais.

O socioambientalismo constrói-se, portanto, a partir da percepção de que as políticas públicas ambientais devem incluir e envolver as comunidades locais, seus conhecimentos tradicionais e suas práticas de manejo ambiental. Constrói-se ainda com base na percepção de que, em um país pobre e com tantas desigualdades sociais, um novo paradigma de desenvolvimento deve promover não apenas a sustentabilidade ambiental (espécies, ecossistemas, processos ecológicos), mas também a sustentabilidade social, contribuindo para a redução da pobreza e da iniquidade, valorizando a diversidade étnica e cultural existentes no país (SANTILLI, 2005).

A expressão "socioambiental" tenciona superar a dicotomina público/privado, afirmando o ambiente como lugar de encontro, onde se dão a totalidade das relações, promovendo um conjunto complexo de condições sociais, morais, naturais e culturais que cercam os seres vivos (MOLINARO, 2007). A esse respeito, Carlos Frederico Marés de Souza Filho (1997, p. 9) afirma: 
[...] o meio ambiente entendido em toda a sua plenitude e de um ponto de vista humanista, compreende a natureza e as transformações que nela vem introduzindo o ser humano. Assim o meio ambiente é composto pela terra, o ar, a flora e a fauna, as edificações, as obras de arte, e os elementos subjetivos e evocativos, como a beleza da paisagem ou a lembrança do inscrições, marcos ou sinais de fatos naturais ou da passagem dos seres humanos. Dessa forma, para compreender o meio ambiente é tão importante a montanha, como a evocação mística que dela faça o povo. Alguns destes elementos existem independente do homem: os chamamos de meio ambiente natural; outros são frutos de sua intervenção e os chamamos de meio ambiente cultural.

A consolidação do socioambientalismo no Brasil fortaleceu a incorporação, pelos movimentos sociais, das lutas e demandas por justiça ambiental, ou seja, a reivindicação de que nenhum grupo de pessoas, sejam grupos étnicos, raciais ou de classe, suporte uma parcela desproporcional de degradação do espaço coletivo. (ACSELRAD; HERCULANO; PÁDUA, 2004). Em outras palavras, determinou uma ressignificação da questão ambiental, a partir de uma "[...] apropriação singular da temática do meio ambiente por dinâmicas sociopolíticas tradicionalmente envolvidas com a construção da justiça social." (ACSELRAD, 2010, p. 108).

A origem da expressão justiça ambiental remonta aos movimentos sociais norteamericanos que a partir da década de 1960 passaram a reivindicar direitos civis às populações afrodescendentes existentes nos EUA, bem como a protestar contra a exposição humana à contaminação tóxica de origem industrial. A partir da experiência norteamericana, a perspectiva da justiça ambiental se difundiu pelo mundo, ganhando contornos bem mais amplos que os originalmente vinculados às lutas contra o racismo ambiental ou contra contaminação tóxica. Atualmente, diversos movimentos sociais globais e regionais integram uma mesma corrente ética de pensamento, denominada de movimento por justiça ambiental (RAMMÊ, 2012). 
Como consequência dessa expansão a expressão injustiça ambiental passou a designar o fenômeno da destinação da maior carga dos danos ambientais decorrentes do processo de desenvolvimento a certas comunidades tradicionais (pequenos agricultores, comunidades de pescadores, comunidades extrativistas, comunidades indígenas e quilombolas), grupos de trabalhadores, grupos raciais discriminados, populações pobres, marginalizadas e vulneráveis.

A perspectiva de atuação do movimento por justiça ambiental, volta-se, portanto, para a justa distribuição do espaço ambiental coletivo entre os seres humanos vivos, bem como para o enfrentamento de toda e qualquer espécie de violações de direitos humanos originadas em contextos de degradação ambiental. Trata-se de uma perspectiva que visa a superação das desigualdades ambientais, rompendo, nos dizeres de Henri Ascelrad (2011), com o senso comum hegemônico de que a poluição é "democrática" e que a degradação ambiental afeta a todos, pouco importando os modos ou locais de vida das pessoas. Ao contrário, tal perspectiva evidencia que são “[...] desiguais as condições de acesso dos diferentes setores da população à proteção ambiental."(ASCELRAD, 2011, p. 40).

O escopo das lutas e demandas do movimento por justiça ambiental, portanto, é o enfrentamento e redução das desigualdades ambientais. Uma perspectiva que procura demonstrar que a exposição da população humana aos riscos ambientais está longe de ser equitativa, reivindicando, para além da necessidade de preservação do meio ambiente e dos recursos naturais, o respeito aos direitos humanos das populações que suportam tais desigualdades.

Desponta nesse cenário, um novo direito, socioambiental, o qual incorpora novos aspectos para além do direito ambiental tradicional, de cunho preponderantemente regulatório: demandas por auto-gestão da produção e estilo de vida de grupos e popu- 
lações, por identidade étnica, por autonomia cultural e contra o racismo ambiental. Esse novo direito (socioambiental) tutela o direito dos povos que vivem em relação de simbiose com o meio ambiente (subsistência direta). Trata-se, portanto, de um direito que "nasce da constatação de que o ambientalismo, desprovido dos anseios das gentes que conformam nossos ambientes, e o socialismo, sem compromisso com o estado geral da terra, não são politicamente sustentáveis." (SANTILLI, 2005, p. 9).

Conforme Fernanda de Salles Cavedon e Ricardo Stanziola Vieira (2007), o socioambientalismo visa a incorporação de fatores estritamente ambientais e de caráter técnico com o seu contexto social, econômico, cultural, étnico e político, além disso, tem uma estreita relação com a criação de condições estruturais mais favoráveis ao exercício da cidadania, através da criação e consolidação de espaços públicos decisórios, entendendo-se que as decisões em matéria ambiental devem ser construídas coletivamente, com a participação direta dos titulares do patrimônio socioambiental. Assim, propugna o desenvolvimento de uma democracia ambiental, capaz de fortalecer a cidadania ambiental e o exercício dos direitos ambientais essenciais, que integram seu núcleo: acesso à informação, participação pública nos processos decisórios e acesso à justiça.

Aliás, a razão de ser do fenômeno jurídico, como bem observa Molinaro (2007) reside justamente na busca do equilíbrio do que tende a opor-se, operando, instrumentalmente, como um processo de adaptação e corrigenda das relações inter-humanas em um espaço social dado. Aí reside o objeto de proteção do direito socioambiental, o qual, numa visão culturalista do direito, é produto do cultural e destina-se a estabelecer um procedimento de proteção e corrigenda dos defeitos de adaptação do ser humano ao seu entorno, aí inseridas as relações humanas e sociais com o meio biótico e abiótico. É, pois, o domínio de regulação do entorno, como define Molinaro (2007, p. 45). 
Portanto, direito socioambiental é o direito que nasce de uma constatação de que não bastam ações promovendo somente a sustentabilidade social ou somente a sustentabilidade dos ecossistemas, é preciso conciliar ambas. Para tanto, faz-se necessário observar a interação que as mais diferentes espécies (não apenas a humana) exercem no meio em que vivem (seu entorno). Essa a razão de a biodiversidade e a sociodiversidade serem os bens jurídicos protegidos pelo direito socioambiental.

\section{O ESTADO SOCIAMBIENTAL E DEMOCRÁTICO DE DIREITO O ÂMBITO DE PROTEÇÃO DO DIREITO SOCIOAMBIENTAL}

A partir da promulgação da Constituição Federal de 1988, e com o amadurecimento de uma leitura constitucional da tutela do ambiente, novas reflexões e percepções surgiram no cenário jurídico-doutrinário brasileiro, identificando na Carta Constitucional brasileira o projeto de uma nova ordem jurídico-ecológica, capaz de tornar convergentes as agendas social e ambiental por meio de uma adequada regulação constitucional socioambiental.

Expoentes dessa abordagem, Sarlet e Fensterseifer (2010) referem que a nova ordem constitucional brasileira é inovadora ao estabelecer claramente a opção por um novo modelo de Estado (Socioambiental) de Direito, o qual resulta de uma convergência da tutela dos direitos sociais e dos direitos ambientais em um mesmo projeto jurídico-político, voltado ao desenvolvimento humano em padrões sustentáveis. Inclui-se nesse projeto jurídico-político socioambiental, portanto, uma noção abrangente e integrada dos direitos econômicos, sociais, culturais e ambientais.

Os autores suprarreferidos destacam, assim, o surgimento de um constitucionalismo socioambiental, ou ao menos a necessidade de se construir tal noção jurídica, que avança para além do constitucionalismo social (SARLET; FENSTERSEIFER, 2010).

Esse constitucionalismo socioambiental também pode ser 
compreendido como um reflexo da contaminação, no espaço jurídico-político, de valores ecológicos, socioambientais e dos princípios de justiça ambiental. Este, aliás, é o grande desafio do Estado Socioambiental e Democrático de Direito: tornar-se um modelo de Estado onde a justiça ambiental se torne um referencial normativo permanente, em todas as esferas de atuação estatal. A esse respeito, Leite (2008, p. 158) afirma:

A grande e, talvez, a maior dificuldade em construir um Estado de Direito Ambiental é transformá-lo em um Estado de justiça ambiental. [...] Para se formular uma política ambiental com justiça ambiental, é necessário que o Estado se guie por princípios que vão se formando a partir da sedimentação das complexas questões suscitadas pela crise ambiental.

O Estado Socioambiental de Direito, para assumir a condição de "Estado de Justiça Ambiental", não pode ser indiferente às práticas discriminatórias que onerem de forma injusta o modo de vida, o território, a cultura, as tradições e a saúde de indivíduos ou comunidades humanas, em virtude de raça, condição socioeconômica, localização geográfica, dentre outros fatores; também não pode ser indiferente às práticas e comportamentos que venham afetar a dignidade intrínseca às demais formas de vida não humanas e o equilíbrio ecológico dos ecossistemas.

Vale destacar aqui a lição de Canotilho (1999, p. 41), para quem o Estado de Direito legítimo é um verdadeiro Estado de Justiça, mas para sê-lo necessita permanentemente incorporar "[...] princípios e valores materiais que permitam aferir do carácter justo ou injusto das leis, da natureza justa ou injusta das instituições e do valor ou desvalor de certos comportamentos". Sem esta abertura reflexiva o Estado de Direito sucumbe na tarefa de regular os novos fenômenos sociais injustos, tornando-se aquilo que Canotilho (1999) define por Estado de não-direito, legitimador de injustiças. Amolda-se a tais considerações a observação de Molinaro (2007, p. 96): 
Essa reflexão só pode ser exercida por uma crítica que atenda aos princípios de um direito justo e de uma Justiça que esteja preparada para interpretar justamente o direito, vale dizer, a necessidade de, em momentos definidos da história, negar a realidade do fático e de sua injusta realidade, propugnando por um "anseio" universal de esperança [...] (Grifos do autor).

Um dos caminhos que a doutrina especializada vem trilhando para identificar o marco normativo desse novo modelo de Estado passa pela redefinição do conceito de dignidade humana, que passa a ser concebido como dotado de dupla dimensão, social e ecológica.

A dimensão social (ou comunitária) da dignidade da pessoa humana, como referem Sarlet e Fensterseifer (2011, p. 59), implica um permanente "[...] olhar para o outro, visto que o indivíduo e a comunidade são elementos integrantes de uma mesma (e única) realidade político-social". A dimensão social da dignidade da pessoa humana, portanto, enfatiza não apenas um compromisso moral, mas também jurídico do Estado e dos particulares para com a construção de uma estrutura político-social que assegure um mínimo existencial social para a vida humana com dignidade.

Já a dimensão ecológica da dignidade humana não se restringe a algo puramente biológico ou físico, mas contempla, segundo Sarlet e Fensterseifer (2011, p. 60), “[...] a qualidade de vida como um todo, inclusive do ambiente em que a vida humana (mas também a não-humana) se desenvolve". A dimensão ecológica da dignidade humana, portanto, amplia o conteúdo da dignidade da pessoa humana de modo a assegurar um padrão de qualidade e segurança ambiental mais elevado aos seres humanos.

Percebe-se, assim, a correlação existente entre a perspectiva ampliada da justiça ambiental e a redefinição conceitual da dignidade humana. Dessa remodelação do conceito de dignidade humana exsurge a ideia de um mínimo existencial ecológico (ou socioambiental). Sobre isso, Sarlet e Fensterseifer (2010, p. 14) observam: 
[...] para além dos direitos já identificados doutrinariamente como "possíveis" integrantes da noção de um mínimo existencial (reconhecidamente controversa, a despeito de sua popularidade), como é o caso de uma moradia digna, de assistência social, de uma alimentação adequada, entre outros, é nosso intento sustentar a inclusão nesse elenco da qualidade ambiental, objetivando a garantia de uma existência humana digna e saudável, especialmente no que diz com a construção de um bem-estar existencial que tome em conta também a qualidade do ambiente.

Em essência o mínimo existencial ecológico se traduz num princípio basilar do Estado Socioambiental e Democrático de Direito, pautado por valores éticos de justiça social e ambiental. Decorre, sobretudo, do reconhecimento da jusfundamentalidade do direito ao ambiente ecologicamente equilibrado e da constatação de como os atuais processos de degradação ambiental atingem em cheio a dignidade da vida humana. Com efeito, para além de um mínimo existencial social, o mínimo existencial ecológico (ou socioambiental) adquire notoriedade como um padrão mínimo de qualidade ambiental para a concretização da dignidade de indivíduos e coletividades humanas.

Cabe destacar que a edificação desse Estado Socioambiental e Democrático de Direito também passa pela consolidação de uma ordem constitucional mediante o reconhecimento direitos (e deveres!) fundamentais socioambientais, os quais decorrem de uma compreensão integrada e interdependente dos direitos sociais e da proteção do ambiente, porquanto como bem observam Sarlet e Fensterseifer (2010, p. 32), a proteção ambiental “[...] está diretamente relacionada à garantia dos direitos sociais, já que o gozo desses últimos é dependente de condições ambientais favoráveis".

Portanto, o que aqui se define por direito socioambiental engloba um sistema de direitos e deveres fundamentais de natureza coletiva ou difusa, baseado nos seguintes pilares: proteção ambiental e equilíbrio ecológico (arts. 170, VI e 225 da CF/88); dignidade da pessoa humana (art. 1ํ, III, da CF/88); construção de uma sociedade mais justa e solidária (art. 3ํㅗ, I, da CF/88); 
combate e repúdio ao racismo e a quaisquer formas de discriminação (arts. 3ํㅡㄴ IV e 4ํㅡ, VIII, da CF/88); autodeterminação dos povos (art. 4ํㅗ III, da CF/88); prevalência dos direitos humanos (art. 4ํㅗ II, da CF/88) valores étnicos, culturais (arts. 215, 216, 231 e 232 da CF/88); função socioambiental da propriedade (arts. 170, III, e 186, da CF/88); e redução das desigualdades regionais e sociais (art. 170, VII, da CF/88). Nesse sentido, abarcam um conjunto de normas jurídicas destinadas à proteção da biodiversidade e da sociodiversidade (étnica e cultural) no Brasil.

São, portanto, nessa perspectiva, direitos e deveres fundamentais com espírito coletivo. São novos direitos, de novos sujeitos, fundados na multietnicidade e no pluralismo. Decorrem, portanto, de uma leitura sistêmica e integrada da Constituição Federal. Nesse sentido, a lição de Carlos Frederico Marés de Souza Filho (2002, p. 23):

Ao reconhecer e proteger direitos coletivos como ao meio ambiente, ao patrimônio cultural, aos próprios valores étnicos e impor à propriedade privada restrições fundadas nestes direitos, a Constituição de 1988 abre as portas para um novo direito fundado no pluralismo, na tolerância, nos valores culturais locais, na multietnicidade, que rompe com a lógica excludente do Estado Constitucional e seu Direito único. Mas apenas abriu as portas, o sistema, com sua força e prepotência, não tem permitido que por ela entrem os povos.

Ainda, segundo essa perspectiva, o reconhecimento dos direitos e deveres fundamentais socioambientais objetiva superar a clássica divisão metodológica adotada por grande parte da doutrina do direito ambiental que divide o conceito de meio ambiente em natural, artificial, cultural e do trabalho, a qual, na grande maioria das vezes, impede que os operadores do direito compreendam, de forma sistêmica e integrada, a totalidade dos direitos que integram a equação socioambiental.

0 direito socioambiental, portanto, se apresenta como uma resposta necessária do Direito à problemática socioambiental 
que se reflete, como bem observa Leff (2001), em uma crise civilizacional, na qual o sonho dourado do desenvolvimento e modernização, guiado pelo crescimento econômico e pelo progresso tecnológico, apoia-se em um regime jurídico forjado por uma ideologia de liberdades individuais que privilegia os interesses privados em detrimento dos coletivos. E mais, o direito socioambiental emerge, segundo Leff (2001), do "grito" da natureza e das lutas sociais que reivindicam justiça em processos de degradação social e cultural por meio da exploração do ambiente. Seu fortalecimento, portanto, decorre de uma exigência de respeito às identidades étnicas forjadas ao longo da história de um povo e da relação travada com seu entorno ecológico.

\section{CONSIDERAÇÕES FINAIS}

De todo o exposto, pode-se afirmar ser clara a relação e a influência que a perspectiva da justiça ambiental exerce sobre o desenvolvimento e fortalecimento do direito socioambiental no Brasil.

Justiça ambiental é uma perspectiva teórico-prática que nasce das reivindicações e movimentos de resistência e luta social. É , pois discurso e prática. É a luta dos movimentos sociais e das comunidades pobres, vulneráveis ou tradicionais contra a injustiça ambiental, contra as desigualdades ambientais verificadas na vida cotidiana, pois infelizmente, a escassez de recursos naturais e degradação dos ecossistemas afetam de modo desigual, e normalmente injusto, diferentes grupos sociais ou áreas geográficas, recaindo de modo mais intenso sobre as populações de baixa renda, comunidades negras e grupos indígenas, justamente por sua maior vulnerabilidade e menor possibilidade de reivindicar justiça e direitos.

O surgimento e fortalecimento do direito socioambiental é reflexo desse fenômeno injusto. É uma forma de corrigenda dos defeitos de adaptação dos tempos atuais. E a justiça ambiental 
é o objetivo a ser alcançado, na medida em que reconhece que os impactos ambientais não são distribuídos equitativamente no cenário social.

Os direitos socioambientais por sua vez pregam que precisamos levar em conta não só o "natural", mas também "social" e o "cultural", pois evidencia a necessidade de valorizar e preservar as diferentes culturas e os modos alternativos de vida e subsistência.

É notório que o modelo atual de desenvolvimento, baseado no crescimento ilimitado e, por consequência, no uso intensivo e desmedido dos recursos naturais, somente se viabiliza porque distribui de forma desigual seus impactos negativos entre grupos vulnerabilizados que têm menos recursos políticos, financeiros e informacionais para se protegerem, e é somente a partir da efetividade dos direitos e deveres fundamentais socioambientais, com foco na justiça ambiental, que surgirão condições de frear o desenvolvimento descontrolado e indiferente às injustiças ambientais causadas.

Somente a percepção de que a crise socioambiental contemporânea não é democrática conduz à compreensão de que há algo errado neste modelo de desenvolvimento.

Conclui-se que muito embora os direitos e deveres fundamentais socioambientais sejam uma realidade presente no projeto jurídico-político nacional desde a promulgação da Constituição Federal de 1988, sua efetividade ainda está longe de ser uma realidade em nosso país, muito pela ausência de uma visão sistêmica e integrada de seu regime jurídico.

Algumas causas podem ser apontadas, mesmo que de forma quase intuitiva (e que carecem de maior investigação futura): (a) falta de especificação concreta do conteúdo desses direitos e deveres fundamentais (indeterminabilidade da prestação ou abstenção devidas); (b) indeterminabilidade dos bens socioambientais constitucionalmente protegidos; (c) indeterminabilidade do conteúdo do mínimo existencial socioambiental; (d) ausência 
de mecanismos processuais adequados para a tutela dos direitos socioambientais; (e) falta de tradição cultural e jurídica para a tutela desses novos direitos; (f) confronto entre o sistema jurídico de direito privado com o regime jurídico dos direitos socioambientais; ( $\mathrm{g}$ ) formalismo excessivo para o acesso à justiça; (h) invisibilidade de muitos dos sujeitos coletivos titulares de direitos socioambientais (comunidades indígenas, quilombolas, populações tradicionais); e (i) falta de percepção pelas próprias vítimas de violações de seus direitos fundamentais socioambientais.

Portanto, muito embora evidencie-se no campo teórico o marco jurídico-constitucional socioambiental, resultado da convergência necessária da tutela dos direitos sociais e dos direitos ambientais num mesmo projeto jurídico-político, na prática tais direitos e deveres são constantemente violados, acarretando um grande número de conflitos socioambientais, a demonstrar que há uma desconexão entre o projeto jurídico-político nacional e a realidade.

Uma desconexão que evidencia a necessidade de aprofundar os estudos sobre a temática do socioambientalismo de modo a identificar a contribuição que o Direito tem a dar para ampliar a efetividade desses (novos) direitos e deveres fundamentais, mediante técnicas mais adequadas de regulação do risco socioambiental no Brasil.

\section{REFERÊNCIAS}

ACSELRAD, Henri. Ambientalização das lutas sociais. Estudos avançados, v. 24, no 68, São Paulo, 2010, p. 103-119.

ACSELRAD, Henri. Introdução. In: FEDERAÇÃO DE ÓRGÃOS PARA A ASSISTÊNCIA SOCIAL E EDUCACIONAL - FASE. Relatório Síntese: Projeto de Avaliação de Equidade Ambiental como instrumento de democratização dos procedimentos de avaliação de impacto de projetos de desenvolvimento. Rio de Janeiro: FASE/ETTERN/IPPUR/UFRJ, 2011.

ACSELRAD, Henri; HERCULANO, Selene; PÁDUA, José Augusto. A justiça ambiental e a dinâmica das lutas socioambientais no Brasil: uma 
introdução. In: ACSELRAD, Henri; HERCULANO, Selene; PÁDUA, José Augusto (Org.). Justiça Ambiental e Cidadania. Rio de Janeiro: Relume Dumará, 2004.

CANOTILHO, José Joaquim Gomes. Estado de direito. Lisboa: Gradiva, 1999.

CAVEDON, Fernanda de Salles; VIEIRA, Ricardo Stanziola. Socioambientalismo e justiça ambiental como paradigma para o sistema jurídico-ambiental: estratégia de proteção da sóciobiodiversidade no tratamento dos conflitos jurídico-ambientais. In: Âmbito Jurídico, Rio Grande, X, n. 40, abr 2007. Disponível em: <http://www.ambito-juridico.com.br/ site/index.php?n_link=revista_artigos_leitura\&artigo_id=1736>. Acesso em maio 2016.

LEFF, Enrique. Los derechos del ser colectivo y la reapropiación social de la naturaleza: a guisa de prólogo. In: LEFF, Enrique (Coord.). Justicia Ambiental: construción y defensa de los nuevos derechos ambientales, culturales y colectivos en América Latina. México: PNUMA, 2001.

LEITE, José Rubens Morato. Sociedade de Risco e Estado. In: CANOTILHO, José Joaquim Gomes; LEITE, José Rubens Morato. Direito constitucional e ambiental brasileiro. São Paulo: Saraiva, 2008, p. 130-204.

MARÉS DE SOUZA FILHO. Carlos Frederico. Bens culturais e proteção jurídica. Porto Alegre: Unidade Editorial da Prefeitura, 1997.

MARÉS DE SOUZA FILHO. Carlos Frederico. Introdução ao Direito Socioambiental. In: LIMA, André (Org.). O Direito para o Brasil Socioambiental. Porto Alegre: Sérgio Fabris Editora, 2002, p. 21-48.

MOLINARO, Carlos Alberto. Direito ambiental: proibição de retrocesso. Porto Alegre: Livraria do Advogado, 2007.

RAMMÊ, Rogério Santos. Da justiça ambiental aos direitos e deveres ecológicos: conjecturas político-filosóficas para uma nova ordem jurídico-ecológica. Caxias do Sul: Educs, 2012.

SANTILLI, Juliana. Socioambientalismo e novos direitos: proteção jurídica à diversidade biológica e cultural. São Paulo: Peirópolis, 2005.

SARLET, Ingo Wolfgang; FENSTERSEIFER, Tiago. Direito constitucional ambiental. São Paulo: Revista dos Tribunais, 2011.

SARLET, Ingo Wolfgang; FENSTERSEIFER, Tiago. Estado socioambiental e mínimo existencial (ecológico?): algumas aproximações. In: SARLET, Ingo Wolfgang (Org.). Estado socioambiental e direitos fundamentais. Porto Alegre: Livraria do Advogado, 2010, p. 11-38. 